\title{
Visualizing the Newtons Fractal from the Recurring Linear Sequence with Google Colab: An Example of Brazil X Portugal Research
}

\author{
Francisco Regis Vieira Alves ${ }^{1^{\star}}$, Renata Passos Machado Vieira ${ }^{2}$, Paula Maria Machado Cruz Catarino ${ }^{3}$ \\ ${ }^{7}$ Federal Institute of Science and Technology of Ceara, BRAZIL \\ ${ }^{2}$ Federal Institute of Education, Science and Technology, Fortaleza, BRAZIL \\ ${ }^{3}$ UTAD - University of Trás-os-Montes and Alto Douro, PORTUGAL \\ *CORRESPONDENCE: $\square$ fregis@ifce.edu.br
}

\begin{abstract}
In this work, recurrent and linear sequences are studied, exploring the teaching of these numbers with the aid of a computational resource, known as Google Colab. Initially, a brief historical exploration inherent to these sequences is carried out, as well as the construction of the characteristic equation of each one. Thus, their respective roots will be investigated and analyzed, through fractal theory based on Newton's method. For that, Google Colab is used as a technological tool, collaborating to teach Fibonacci, Lucas, Mersenne, Oresme, Jacobsthal, Pell, Leonardo, Padovan, Perrin and Narayana sequences in Brazil and Portugal. It is also possible to notice the similarity of some of these sequences, in addition to relating them with some figures present and their corresponding visualization.
\end{abstract}

Keywords: teaching, characteristic equation, fractal, Google Colab, Newton's method, sequences

\section{INTRODUCTION}

Studies referring to recurring sequences are being found more and more in the scientific literature, exploring not only the area of Pure Mathematics, with theoretical instruments used in algebra, but also in the area of Mathematics teaching and teacher training. In the work of Alves (2017), Oliveira and Alves (2019), and Souza and Alves (2018), one can perceive the use of research and teaching methodologies for the study of these sequences, emphasizing the use of technological resources as facilitating tools for this process. In addition, the existing works deal only with one or two recurring sequences, not addressing them all in a single research or systematic scientific report.

In turn, according to Protázio, Oliveira, and Protázio (2019), Mathematics software can be educational once the teacher develops strategies to achieve his educational objective, before exploring them. They also report that the use of educational software is a promising tool for teaching Mathematics and exploring visualization and, we add, for the training of Mathematics teachers in Brazil and Portugal.

Through this perspective, a proposal was conceived, in which it explored the teaching of the roots of the characteristic equations of recurrent and linear sequences, through Newton's fractal, using Google Colab as a computational tool to aid this analysis, with emphasis on its character visualization, originated in $2 \mathrm{D}$ and $3 \mathrm{D}$ representations. A study of the historical and epistemological process of these sequences is also inserted before investigating their respective roots. When establishing a direct division of a term in the sequence by its predecessor, this numerical ratio converges-to a certain number, being, therefore, one of the real root of the

Article History: Received 15 March $2020 \bullet$ Revised 13 May $2020 \bullet$ Accepted 13 May 2020

(C) 2020 by the authors; licensee Modestum Ltd., UK. Open Access terms of the Creative Commons Attribution 4.0 International License (http://creativecommons.org/licenses/by/4.0/) apply. The license permits unrestricted use, distribution, and reproduction in any medium, on the condition that users give exact credit to the original author(s) and the source, provide a link to the Creative Commons license, and indicate if they made any changes. 
Table 1. Convergence ratio of the ratio of the elements of the Fibonacci sequence $f_{n}=\frac{F_{n+1}}{F_{n}}$

\begin{tabular}{cccc}
\hline $\boldsymbol{n}$ & $\boldsymbol{f}_{\boldsymbol{n}}$ & $\boldsymbol{n}$ & $\boldsymbol{f}_{\boldsymbol{n}}$ \\
\hline 1 & 1 & 6 & 1.625 \\
\hline 2 & 2 & 7 & 1.615384615 \\
\hline 3 & 1.5 & 8 & 1.619047619 \\
\hline 4 & $1.666 \ldots$ & 9 & 1.617647059 \\
\hline 5 & 1.6 & 10 & 1.618181818
\end{tabular}

Source: Elaborated by the authors

characteristic equation. Thus, each equation presents as a solution at least one real root, which is still related to the sequence through its convergence relationship.

In this study an analysis of the roots of the characteristic equations of the recurrent and linear sequences is performed, using the computational resource of Google Colab, based on the work of Alves and Vieira (2020), Vieira, Alves, and Catarino (2019). This tool assists the analysis of these roots, through the Newton fractal method, covered only in works of pure mathematics, not being approached for teaching. For this, the historical context of the Fibonacci, Lucas, Mersenne, Oresme, Jacobsthal, Pell, Leonardo, Padovan, Perrin sequences and, finally, the Narayana sequence are presented. We then proceed with a brief explanation of Newton's method, and so we seek to analyze the roots through fractal theory, in view of the interest in emphasizing the visualization of certain properties.

\section{RECURRENT AND LINEAR SEQUENCES}

A sequence is said to be recurrent and linear, as it presents an infinite number of terms, and is therefore obtained by means of a mathematical formula in which it needs to know its predecessors, in addition to its initial values (Zierler, 1959). This formula is called a recurrence relation, being represented by an equation, in which, recursively, it defines the sequence. Thus, each term in the sequence is like a function of the previous terms, fixing their respective initial values. With that, we have that this relationship, in a recurring and linear sequence, is described as follows: $a_{n}=c_{1} a_{n-1}+c_{2} a_{n-2}+\ldots+c_{k} a_{n-k}$, where $c_{1}, c_{2}, \ldots, c_{k}$ are the coefficients and elements $a_{n-1}, a_{n-2}, \ldots, a_{n-k}$ are the terms of the recurring sequence.

Every sequence also has a characteristic polynomial or characteristic equation, which is obtained through the fundamental relationship of recurrence, given by the general formula: $x^{n}-c_{1} x^{n-1}-c_{2} x^{n-2}-\ldots-c_{k} x^{n-k}=$ 0 (Forbes, 2014).

It should also be noted that a sequence is said to be linear, only when presenting its function as being of the first degree. However, its respective characteristic equation may be of higher orders. Then, we will carry out a brief historical study (Alves, 2017) referring to recurring and linear sequences, having as precursor the Fibonacci sequence, being, therefore, of second order.

\section{The Fibonacci Sequence}

Introduced in the Middle Ages in Europe, the Fibonacci sequence was created by the mathematician Leonardo de Pisa (1180-1250), still considered the precursor sequence for the origin of similar ones. Having their character of mathematical popularization according to a reproduction model of immortal rabbits, these numbers also raise the question of the reproduction of drones, however, this recurrence model was already known by Indian mathematicians, centuries before (Singh, 1985). Some applications of this sequence are seen in several branches of scientific knowledge and, still, in the human body. On Monalisa's face, we find the formation of the Fibonacci spiral, building the rectangle considered perfect (Kbott, 2020).

The recurrence formula for this second order sequence is given by: $F_{n}=F_{n-1}+F_{n-2}, n \geq 2$, still having the following initial values $F_{0}=0, F_{1}=1$. Considering another sequence, indicated $f_{n}$, in the condition that $f_{n}=$ $\frac{F_{n+1}}{F_{n}}$, we will explore its convergence through Table 1, observing the algebraic behavior and numerical of the following limit indicated by $\lim _{n \rightarrow \infty} f_{n}=\lim _{n \rightarrow \infty} \frac{F_{n+1}}{F_{n}} \approx 1.61=\phi \in I R$, known as the gold number.

Furthermore, we have to start from the recurrence and the relationship involving the quotients $\lim _{n \rightarrow \infty} \frac{F_{n+1}}{F_{n}}=$ $\phi$, we can obtain its characteristic equation $\phi^{2}-\phi-1=0$, originating from the following relations described below: 


$$
\begin{aligned}
& \frac{F_{n}}{F_{n-1}}=\frac{F_{n-1}}{F_{n-1}}+\frac{F_{n-2}}{F_{n-1}} \\
& \leftrightarrow \phi=1+\frac{1}{\frac{F_{n-1}}{F_{n-2}}} \\
& \leftrightarrow \phi=1+\frac{1}{\phi} \\
& \leftrightarrow \phi^{2}-\phi-1=0
\end{aligned}
$$

\section{The Lucas Sequence}

When studying the Fibonacci sequence, the French mathematician Édouard Anatole Lucas (1842-1891), created the Lucas sequence, having its fundamental recurrence relationship identical to the Fibonacci numbers and formulated by $L_{n}=L_{n-1}+L_{n-2}, n \geq 2$ differentiating it only in relation to its initial numerical values chosen, given by $L_{0}=2, L_{1}=1$. With that, we have that the characteristic equation of these numbers is similar to that of Fibonacci, given by the polynomial equation $\phi^{2}-\phi-1=0$. In addition to its convergence relation, corresponding to the ratio of the terms, interconnected with the gold number and other properties similar to the Fibonacci numbers.

E. Lucas was motivated to study divisibility and factorization issues, elaborating a problem regarding the content of combinatorial analysis, in which he says: how many ways can $\mathrm{n}$ couples sit in $2 \mathrm{n}$ different chairs around a circle so that people in the same sex do not feel together and that no man stands by his wife?

This question was raised primarily by Peter Guthrie Tait (1831-1901), but a few years later Lucas modified that question. But, only in 1943, Irving Kaplansky (1917-2006) found a solution to the classic problem and published his work, therefore, counting the number of existing ways to seat a certain number of couples around a round table, alternating still between men and women (Kaplansky, 1943).

Known for the problem of the tower of Hanoi, E. Édouard Lucas also proved a way to obtain Fermat's theorem and performed several tests for prime numbers, calculating, without the aid of computational resources, the largest prime number with 39 digits, during many years. Based on this, he managed to establish a relationship between the twelfth term of the prime number and the Mersenne numbers, which will be studied in the next subsection. There are many applications of these numbers in the areas of Applied Mathematics, Linear Algebra, Computer Sciences, Physics, Biology and among others found in Koshy's work (Koshy, 2001). In the subsequent section we will discuss some properties about the Mersenne sequence. In general, this sequence is disregarded by authors of History of Mathematics books adopted in Brazil.

\section{The Mersenne Sequence}

Formulated by the French mathematician Marin Mersenne (1588-1648), the Mersenne sequence is a second order sequence, with its recurrence defined as: $M_{n}=3 M_{n-1}-2 M_{n-2}, n \geq 2$ and having the initial numerical values defined as follows $M_{0}=0, M_{1}=1$.

In turn, there are still the prime numbers of Mersenne, they are denoted by $M_{n}=2^{n}-1$, where $n$ it is a non-negative number (Catarino, Campos, \& Vasco, 2016). Through a simple mathematical calculation, it is possible to demonstrate that if it $M_{n}$ is a prime number, then $n$ it is a prime number, although $M_{n}$ not all are prime. When $M_{n}$ it is a prime number, it is called a Mersenne prime. The search for Mersenne's cousins is still a current and active issue in number theory, combinatorics, computer science and coding theory, since they have a connection with perfect numbers. On the other hand, the Mersenne sequence is less popular in the literature related to the historical and mathematical context. In the mathematical problem of the Tower of Hanoi, for example, to solve a puzzle with a disk tower, it is necessary to use Mersenne's number formula, assuming that no mistake was made (Ford, Luca, \& Shparlinski, 2009; Koshy \& Gao, 2013).

On the other hand, analyzing the subsequence called $m_{n}=\frac{M_{n+1}}{M_{n}}$, we will explore its convergence relationship, with a view to obtaining the characteristic equation. Thus, observing Table 2, we can see mathematically that we will have the limit $\lim _{n \rightarrow \infty} m_{n}=\lim _{n \rightarrow \infty} \frac{M_{n+1}}{M_{n}} \approx 2=\mu \in I R, \mu=2$ known as metallic copper number. 
Table 2. Convergence ratio of the ratio of the elements of the Mersenne sequence $m_{n}=\frac{M_{n+1}}{M_{n}}$

\begin{tabular}{cccc}
\hline $\boldsymbol{n}$ & $\boldsymbol{n}$ & $\boldsymbol{n}$ & $\boldsymbol{m}_{\boldsymbol{n}}$ \\
\hline 1 & 3 & 6 & 2.015873016 \\
\hline 2 & $2.333 \ldots$ & 7 & 2.007874016 \\
\hline 3 & 2.142857143 & 8 & 2.003921569 \\
\hline 4 & 2.066666667 & 9 & 2.001956947 \\
\hline 5 & 2.032258065 & 10 & 2.000977517
\end{tabular}

Source: Elaborated by the authors

Table 3. Convergence ratio of the ratio of the elements of the Oresme sequence $o_{n}=\frac{o_{n+1}}{O_{n}}$

\begin{tabular}{cccc}
\hline $\boldsymbol{n}$ & $\boldsymbol{o}_{\boldsymbol{n}}$ & $\boldsymbol{n}$ & $\boldsymbol{o}_{\boldsymbol{n}}$ \\
\hline $\mathbf{1}$ & 1 & 11 & 0.545454545 \\
\hline $\mathbf{2}$ & 0.75 & 12 & 0.541666667 \\
\hline $\mathbf{3}$ & 0.666666667 & 13 & 0.538461538 \\
\hline $\mathbf{4}$ & 0.625 & 14 & 0.535714286 \\
\hline $\mathbf{5}$ & 0.6 & 15 & 0.533333333 \\
\hline $\mathbf{6}$ & 0.583333333 & 16 & 0.53125 \\
\hline $\mathbf{7}$ & 0.571428571 & 17 & 0.529411765 \\
\hline $\mathbf{8}$ & 0.5625 & 18 & 0.527777778 \\
\hline $\mathbf{9}$ & 0.555555556 & 19 & 0.526315789 \\
\hline $\mathbf{1 0}$ & 0.55 & 20 & 0.525 \\
\hline
\end{tabular}

Source: Elaborated by the authors

With that, we have the characteristic equation $\mu^{2}-3 \mu+2=0$ that is determined below:

$$
\begin{aligned}
& \frac{M_{n}}{M_{n-1}}=3\left(\frac{M_{n-1}}{M_{n-1}}\right)-2\left(\frac{M_{n-2}}{M_{n-1}}\right) \\
& \leftrightarrow \mu=3-2\left(\frac{1}{\frac{M_{n-1}}{M_{n-2}}}\right) \\
& \leftrightarrow \mu=3-\frac{2}{\mu} \\
& \leftrightarrow \mu^{2}-3 \mu+2=0
\end{aligned}
$$

\section{The Oresme Sequence}

The philosopher, mathematician, medieval scholastic Nicole Oresme (1320-1382), stood out for his studies regarding the graphic representations of qualities and speeds; was the pioneer to establish a notion of fractional symbolic forms, also suggesting a notation, in addition to considering a pattern of increasing speed without limit and other representations. Thus, starting the interval with the unit time, Oresme established speed 1 in the first half of the time, 2 in the next quarter, 3 in the following eighth and so on. With that, he found the infinite sum of rational numbers indicated by $\frac{1}{2}+\frac{2}{4}+\frac{3}{8}+\frac{4}{16}+\ldots+\frac{n}{2^{n}} \ldots=2$. More recently, he then used geometric interpretation to demonstrate such a suggested problem, but there are no published papers on Oresme's research during the Middle Ages (Horadam, 1974). Based on this infinite sum, we have the recurrence of the Oresme sequence, given by $O_{n}=O_{n-1}-\frac{1}{4} O_{n-2}, n \geq 2$, with initial numerical values equal to $O_{0}=0, O_{1}=\frac{1}{2}$. Exploring a subsequence, given by $o_{n}=\frac{o_{n+1}}{O_{n}}$, we have that it converges according to Table 3 .

We then have to $\lim _{n \rightarrow \infty} o_{n}=\lim _{n \rightarrow \infty} \frac{o_{n+1}}{O_{n}} \approx 0.52=\sigma \in I R$, and the characteristic equation determined by $\sigma^{2}-\sigma+$ $\frac{1}{4}=0$ is indicated as follows: 
Table 4. Convergence ratio of the ratio of the elements of the Jacobsthal sequence $j_{n}=\frac{J_{n+1}}{J_{n}}$

\begin{tabular}{cccc}
\hline $\boldsymbol{n}$ & $\boldsymbol{j}_{\boldsymbol{n}}$ & $\boldsymbol{n}$ & $\boldsymbol{j}_{\boldsymbol{n}}$ \\
\hline $\mathbf{1}$ & 1 & 6 & 2.047619048 \\
\hline $\mathbf{2}$ & 3 & 7 & 1.976744186 \\
\hline $\mathbf{3}$ & $1.666 \ldots$ & 8 & 2.011764706 \\
\hline $\mathbf{4}$ & 2.2 & 9 & 1.994152047 \\
\hline $\mathbf{5}$ & 1.909090909 & 10 & 2.002932551 \\
\hline
\end{tabular}

Source: Elaborated by the authors

$$
\begin{aligned}
& \frac{O_{n}}{O_{n-1}}=\frac{O_{n-1}}{O_{n-1}}-\frac{1}{4}\left(\frac{O_{n-2}}{O_{n-1}}\right) \\
& \leftrightarrow \sigma=1-\frac{1}{4}\left(\frac{1}{\frac{O_{n-1}}{O_{n-2}}}\right) \\
& \leftrightarrow \sigma=1-\frac{1}{4} \frac{1}{\sigma} \\
& \leftrightarrow \sigma^{2}-\sigma+\frac{1}{4}=0
\end{aligned}
$$

According to Alves (2019), this second-order sequence has an application in the area of Biology, since from the first two terms, it is possible to estimate the number of parents, grandparents and determine the proportion in any generation. In the subsequent section, we will deal with the case of the sequence named after the work of the mathematician Ernst Erich Jacobsthal (1882 - 1965).

\section{The Jacobsthal Sequence}

Considered as a particularity of the Lucas sequence, the Jacobsthal sequence is used to solve problems related to the content of combinatorial analysis, having a question proposed and resolved by Craveiro (2004), in which it says: the amount of tiles $q_{n}$ that it is possible to calculate for a rectangle (3xn), using two types of tiles, one of them with dimensions (1xt), in white and the other $(2 \times 2)$ in red, according to Jacobsthal numbers. Defining $q_{0}=0$, for a rectangle $(3 \mathrm{x} 1)$, we will have $q_{1}=1$, for a rectangle $(3 \mathrm{x} 2), q_{2}=3$, that is, three types of possible tiles, for a rectangle $(3 \times 3), q_{3}=5$.

Created by the German mathematician Ernest Erich Jacobsthal (1882-1965), these numbers belong to the second order sequence (Alves, 2017), with their respective recurrence formula given by the relation: $J_{n}=J_{n-1}+$ $2 J_{n-2}, n \geq 2$, with the initial numerical values indicated by $J_{0}=0, J_{1}=1$.

De forma a analisar a subsequência, definida como $j_{n}=\frac{J_{n+1}}{J_{n}}$, we can observe a numerical behavior of its convergence visualized in Table 4, realizing that $\lim _{n \rightarrow \infty} j_{n}=\lim _{n \rightarrow \infty} \frac{J_{n+1}}{J_{n}} \approx 2=\mu \in I R$, known as copper number.

It is observed that the subsequence has the same convergence value as the Mersenne sequence. With that, we will analyze the obtaining of the characteristic equation $\mu^{2}-\mu-2=0$, based on the recurrence of the Jacobsthal sequence.

$$
\begin{aligned}
& \frac{J_{n}}{J_{n-1}}=\frac{J_{n-1}}{J_{n-1}}+2\left(\frac{J_{n-2}}{J_{n-1}}\right) \\
& \leftrightarrow \mu=1+2\left(\frac{1}{\frac{J_{n-1}}{J_{n-2}}}\right) \\
& \leftrightarrow \mu=1+2\left(\frac{1}{\mu}\right) \\
& \leftrightarrow \mu^{2}-\mu-2=0
\end{aligned}
$$

\section{The Pell Sequence}

The Pell sequence was created by the English mathematician John Pell (1611-1685), being a second order sequence, given by the fundamental recurrence indicated by, $P_{n}=2 P_{n-1}+P_{n-2}, n \geq 2$ with the initial numerical values $P_{0}=0, P_{1}=1$. Malcolm (2000) reports that despite these numbers presenting the name to 
Table 5. Convergence ratio of the ratio of the elements of the Pell sequence $p_{n}=\frac{P_{n+1}}{P_{n}}$

\begin{tabular}{cccc}
\hline $\boldsymbol{n}$ & $\boldsymbol{j}_{\boldsymbol{n}}$ & $\boldsymbol{n}$ & $\boldsymbol{j}_{\boldsymbol{n}}$ \\
\hline $\mathbf{1}$ & 2 & 6 & 2.414285714 \\
\hline $\mathbf{2}$ & 2.5 & 7 & 2.414201183 \\
\hline $\mathbf{3}$ & 2.4 & 8 & 2.414215686 \\
\hline $\mathbf{4}$ & 2.416666667 & 9 & 2.414213198 \\
\hline $\mathbf{5}$ & 2.413793103 & 10 & 2.414213625 \\
\hline
\end{tabular}

Source: Elaborated by the authors

Table 6. Convergence ratio of the ratio of the elements of the Leonardo sequence $l e_{n}=\frac{L e_{n+1}}{L e_{n}}$

\begin{tabular}{cccc}
\hline $\boldsymbol{n}$ & $\boldsymbol{l e}_{\boldsymbol{n}}$ & $\boldsymbol{n}$ & $\boldsymbol{l e}_{\boldsymbol{n}}$ \\
\hline $\mathbf{1}$ & 1 & 11 & 1.620209059 \\
\hline $\mathbf{2}$ & 3 & 12 & 1.619354839 \\
\hline $\mathbf{3}$ & $1.666 \ldots$ & 13 & 1.618857902 \\
\hline $\mathbf{4}$ & 1.8 & 14 & 1.618539787 \\
\hline $\mathbf{5}$ & $1.666 \ldots$ & 15 & 1.618347694 \\
\hline $\mathbf{6}$ & $1.666 .$. & 16 & 1.618227372 \\
\hline $\mathbf{8}$ & 1.64 & 17 & 1.618153668 \\
\hline $\mathbf{9}$ & 1.634146341 & 18 & 1.618107882 \\
\hline $\mathbf{1 0}$ & 1.626865672 & 19 & 1.618079681 \\
\hline
\end{tabular}

Source: Elaborated by the authors

the mathematician, there are no publications attributed to the name of this researcher, since Pell did not have financial conditions and resources. This mathematician also stood out for developing resolutions for problems involving tables of squares, sums of squares, primes and compounds, logarithms, among others (Walker, 2011). Defining the subsequence $p_{n}=\frac{P_{n+1}}{P_{n}}$, we analyzed its convergence relationship based on Table 5 .

Thus, we can perceive the behavior of the following limit $\lim _{n \rightarrow \infty} p_{n}=\lim _{n \rightarrow \infty} \frac{P_{n+1}}{P_{n}} \approx 2.41=\delta \in I R$, known as the silver number. The characteristic equation indicated by $\delta^{2}-2 \delta-1=0$ is determined as follows:

$$
\begin{aligned}
& \frac{P_{n}}{P_{n-1}}=2\left(\frac{P_{n-1}}{P_{n-1}}\right)+\frac{P_{n-2}}{P_{n-1}} \\
& \leftrightarrow \delta=2+\frac{1}{\frac{P_{n-1}}{P_{n-2}}} \\
& \leftrightarrow \delta=2+\frac{1}{\delta} \\
& \leftrightarrow \delta^{2}-2 \delta-1=0
\end{aligned}
$$

\section{The Leonardo Sequence}

Currently, few researches are found regarding the Leonardo sequence, highlighting the works of Shannon (2019), Catarino and Borges (2020) and Vieira, Alves, and Catarino (2019), defining it as a second order sequence with a recurrence formula $L e_{n}=L e_{n-1}+L e_{n-2}+1, n \geq 2$, with values initials $L e_{0}=L e_{1}=1$. Catarino and Borges (2020) define yet another recurrence relationship given as $L e_{n}=2 L e_{n-1}-L e_{n-3}, n \geq 3$ :. Based on this second recurrence, we can establish a subsequence in order to obtain the characteristic equation. With that, we have $l e_{n}=\frac{L e_{n+1}}{L e_{n}}$, and its convergence relationship, known as the gold number and observed according to Table 6.

We can now determine the following limit $\lim _{n \rightarrow \infty} l e_{n}=\lim _{n \rightarrow \infty} \frac{L e_{n+1}}{L e_{n}} \approx 1.61=\phi \in I R$. Therefore, its respective characteristic equation $\phi^{3}-2 \phi^{2}+1=0$, which is determined as indicated below: 
Table 7. Convergence ratio of the ratio of the elements of the Padovan sequencepa $a_{n}=\frac{P a_{n+1}}{P a_{n}}$

\begin{tabular}{cccc}
\hline $\boldsymbol{n}$ & $\boldsymbol{l e}_{\boldsymbol{n}}$ & $\boldsymbol{n}$ & $\boldsymbol{l}_{\boldsymbol{n}}$ \\
\hline $\mathbf{1}$ & 1 & 11 & 1.3125 \\
\hline $\mathbf{2}$ & 2 & 12 & $1.333 \ldots$ \\
\hline $\mathbf{3}$ & 1 & 13 & 1.3214 \\
\hline $\mathbf{4}$ & 1.5 & 1.3243 \\
\hline $\mathbf{5}$ & $1.333 \ldots$ & 15 & 1.3265 \\
\hline $\mathbf{6}$ & 1.25 & 16 & 1.3230 \\
\hline $\mathbf{7}$ & 1.4 & 17 & 1.3255 \\
\hline $\mathbf{8}$ & 1.28 & 18 & 1.324561 \\
\hline $\mathbf{9}$ & $1.333 \ldots$ & 19 & 1.3245033 \\
\hline $\mathbf{1 0}$ & 1.6 & 20 & 1.325 \\
\hline
\end{tabular}

Source: Elaborated by the authors

$$
\begin{aligned}
& \frac{L e_{n}}{L e_{n-1}}=2\left(\frac{L e_{n-1}}{L e_{n-1}}\right)-\frac{L e_{n-3}}{L e_{n-1}} \\
& \leftrightarrow \phi=2-\left(\frac{1}{\frac{L e_{n-3} L e_{n-2}}{L e_{n-2} L e_{n-1}}}\right) \\
& \leftrightarrow \phi=2-\frac{1}{\phi^{2}} \\
& \leftrightarrow \phi^{3}-2 \phi^{2}+1=0
\end{aligned}
$$

\section{The Padovan Sequence}

After the end of World War II, large churches were destroyed, and with that the architect Hans Van Der Laan (1904-1991) chose to rebuild these churches, thus discovering a new standard of architectural measurement, given by an irrational number, known as plastic number (Voet \& Schoonjans, 2012).

Some time later, the Italian architect Richard Padovan, developed a sequence, having a connection with this plastic number, with an approximate value of 1.32 . Thus, we have a third order sequence, with a recurrence relation given by $P a_{n}=P a_{n-2}+P a_{n-3}, n \geq 3$ and with initial values $P a_{0}=P a_{1}=P a_{2}=1$. Analyzing the subsequence called $p a_{n}=\frac{P a_{n+1}}{P a_{n}}$, we explored its convergence relationship based on Table 7 .

It is possible to determine the behavior of the following limit $\lim _{n \rightarrow \infty} p a_{n}=\lim _{n \rightarrow \infty} \frac{P a_{n+1}}{P a_{n}} \approx 1.32=\psi \in I R$, known as the plastic number. The characteristic equation $\psi^{3}-\psi-1=0$ is obtained, similarly, to the previous cases:

$$
\begin{aligned}
& \frac{P a_{n}}{P a_{n-2}}=\frac{P a_{n-2}}{P a_{n-2}}+\frac{P a_{n-3}}{P a_{n-2}} \\
& \leftrightarrow \frac{P a_{n}}{P a_{n-2}} \frac{P a_{n-1}}{P a_{n-1}}=1+\frac{1}{P a_{n-2}} \\
& \leftrightarrow a_{n-3} \\
& \leftrightarrow \psi^{2}=1+\frac{1}{\psi} \\
& \leftrightarrow \psi^{3}-\psi-1=0
\end{aligned}
$$

\section{The Perrin Sequence}

Similar to the Padovan sequence, we have then the Perrin sequence, created by the French engineer Olivier Raoul Perrin (1841-1910), having the same recurrence and equation characteristic of the Padovan sequence, which we indicate by the fundamental recurrence relation $P e_{n}=P e_{n-2}+P e_{n-3}, n \geq 3$, however, changing only from their initial numerical values $P e_{0}=3, P e_{1}=0, P e_{2}=2$.

It should be noted that during the year 1876 this sequence was mentioned by Édouard Lucas, noting that if $p$ it is a prime number, then it divides $P e_{p}$, thus being a consequence of Fermat's theorem (Adamns, 1982). However, in 1899, Olivier Perrin defined Perrin's sequence as having great importance, particularly in graph theory, using it to discover the coordinates of taxis in urban networks in a confidential manner. Finally, in the 
Table 8. Convergence ratio of the ratio of the elements of the Padovan sequencen $n_{n}=\frac{N_{n+1}}{N_{n}}$

\begin{tabular}{cccc}
\hline$n$ & $n_{n}$ & $n$ & $n_{n}$ \\
\hline $\mathbf{1}$ & 1 & 11 & 1.464285714 \\
\hline $\mathbf{2}$ & 1 & 12 & 1.463414634 \\
\hline $\mathbf{3}$ & 2 & 13 & 1.466666667 \\
\hline $\mathbf{5}$ & 1.5 & 14 & 1.465909091 \\
\hline $\mathbf{6}$ & $1.333 \ldots$ & 15 & 1.465116279 \\
\hline $\mathbf{7}$ & 1.5 & 16 & 1.465608466 \\
\hline $\mathbf{8}$ & 1.5 & 17 & 1.465703971 \\
\hline $\mathbf{9}$ & $1.444 \ldots$ & 18 & 1.465517241 \\
\hline $\mathbf{1 0}$ & 1.461538462 & 19 & 1.465546218 \\
\hline
\end{tabular}

Source: Elaborated by the authors

following section, we will address an example from an hindu mathematical culture e. usually, disregarded and not discussed by authors of History of Mathematics books adopted in Brazil.

\section{The Narayana Sequence}

Having its genesis in the problem in which it says: a cow gives birth to a calf every year. In turn, the calf gives birth to another calf when it is three years old. What is the number of progenies produced by a cow during twenty years? Thus, when solving this problem, we were able to obtain the terms of the Narayana sequence (Ramiréz \& Sirvent, 2015).

The Narayana sequence, was created by the Indian Narayana Pandita (1340 - 1400), as a third order sequence, having its fundamental recurrence $N_{n}=N_{n-1}+N_{n-3}, n \geq 3$, with the initial numerical terms equal to $N_{0}=N_{1}=N_{2}=1$. In search of its characteristic equation, we then have the subsequence named $n_{n}=\frac{N_{n+1}}{N_{n}}$, analyzing its convergence according to Table 8.

With that, we can establish the behavior of the limit $\lim _{n \rightarrow \infty} n_{n}=\lim _{n \rightarrow \infty} \frac{N_{n+1}}{N_{n}} \approx 1.46=\eta \in I R$, and thus obtain the characteristic equation $\eta^{3}-\eta^{2}-1=0$ as we determined, then, just below:

$$
\begin{aligned}
& \frac{N_{n}}{N_{n-1}}=\frac{N_{n-1}}{N_{n-1}}+\frac{N_{n-3}}{N_{n-1}} \\
& \leftrightarrow \eta=1+\frac{1}{\frac{N_{n-3}}{N_{n-1}} \frac{N_{n-2}}{N_{n-2}}} \\
& \leftrightarrow \eta=1+\frac{1}{\eta^{2}} \\
& \leftrightarrow \eta^{3}-\eta^{2}-1=0
\end{aligned}
$$

\section{NEWTON'S METHOD AND THE FRACTAL THEORY}

In view of the characteristic equations of all the recurring sequences indicated above, it is important to obtain their roots, since the result of a real root is related to the convergence relationship between the neighboring terms of the sequence, making it necessary to obtain these results precisely.

For this, in this work, Newton's method is used, as a theory known for calculating successive approximations of the polynomial zeros of the characteristic equations, which are transformed into functions. That done, there can be a rapid convergence of this mathematical function, if the iteration started with a value close to its respective root. If the iteration has started with certain values far from the exact value of the root, great care must be taken to avoid errors during the use of this method (Teodoro \& Aguiar, 2015).

One way to exemplify this method is found in the work of Vieira, Alves, and Catarino (2019), Alves and Vieira (2020) and Teodoro and Aguilar (2015), in which they carry out an example of Newton's method, using only the mathematical formula, without the aid of computational resources. In these works, we can see that visualization plays an important strategic role, aiming to communicate and transmit mathematical ideas and notions. 
On the other hand, this is only one of the means of obtaining the roots of the equation, and is therefore considered easy to solve because the equation is second order. However, as seen in the previous section, it is clear that there are some sequences with higher order equations, resulting in some complex numbers, which makes the method even more difficult.

In fact, fractal theory consists of an art in which it transforms mathematical functions into a medium, which can be images, music and $2 \mathrm{D}$ or $3 \mathrm{D}$ animations. A fractal is nothing more than a geometric object that can be divided into several parts, where each is similar to another fractional part from the original object. This term was used in 1975 by the French mathematician Benoit Mandelbrot, giving the real meaning of breaking. Thus, according to Assis et al. (2008) "a fractal is an object that presents invariance in its form as the scale, under which it is analyzed."

There are many properties linked to this theory, such as: self-similarity, infinite complexity and dimension. The first is identified through the proportion of the figure, where a part of the figure is then removed, and thus a similarity with the other parts of the figure as a whole is perceived. For the second property, a reference is then made around the figure generation process, where once defined as a fractal, it is considered a recursive figure. Thus, when executing a code or procedure, a running sub-procedure is found, based on the initial procedure. Finally, the last property is given by a fractional dimension, different from Euclidean geometry (Takayasy, 1990).

In view of this, it was then thought of using a computational resource to assist and facilitate the search for these roots, thus using the fractal theory linked to Newton's method. With that, we will use the Google Colab tool, which deals with a free Google resource, where you can develop a programming code in the Phyton language, to facilitate the search for the roots of the equations. This tool is hosted by Google, with no need for a computer with a large memory capacity, since it is then run in the cloud. This feature has some libraries already installed, and the files are then saved to Drive, making their configuration quick and easy.

In the next section, we will analyze Newton's fractals generated based on Google Colab, thus performing the search for their real roots.

\section{NEWTON FRACTAL ANALYSIS OF RECURRENT SEQUENCES WITH GOOGLE COLAB}

In this section, Newton's fractals will be generated and analyzed using Google Colab as an auxiliary tool for plotting the figures. According to the code developed in Phyton, the equations were transformed into functions, making it possible to generate fractals according to Newton's method. With the aim of seeking the values of the real roots of the sequences, we then have to discuss only the solutions that have a connection with the convergence of the studied sequences.

Due to the similarity of the recurrence formula and the characteristic equation of some sequences, these will be discussed together. It is also possible to observe that because there are sequences with equations very similar to others, your generated fractals will have similar formats. Finally, these fractals are related to objects found in nature, establishing a possible application of this sequence content in everyday life.

\section{Fibonacci and the Lucas fractal}

In order to explore the roots of the characteristic equation $\phi^{2}-\phi-1=0$ of these two sequences, indicated by, then we have Figure 1, showing the Newton fractal by Fibonacci and Lucas. 


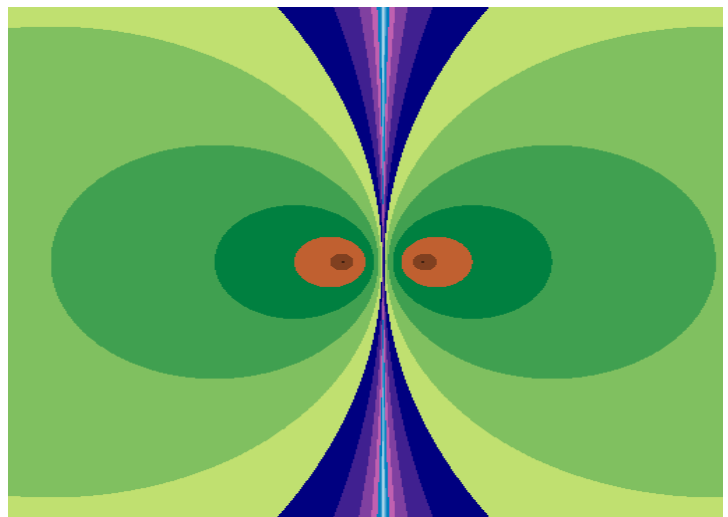

Figure 1. Newton's 2D fractal of the Fibonacci and Lucas sequence Prepared by the authors
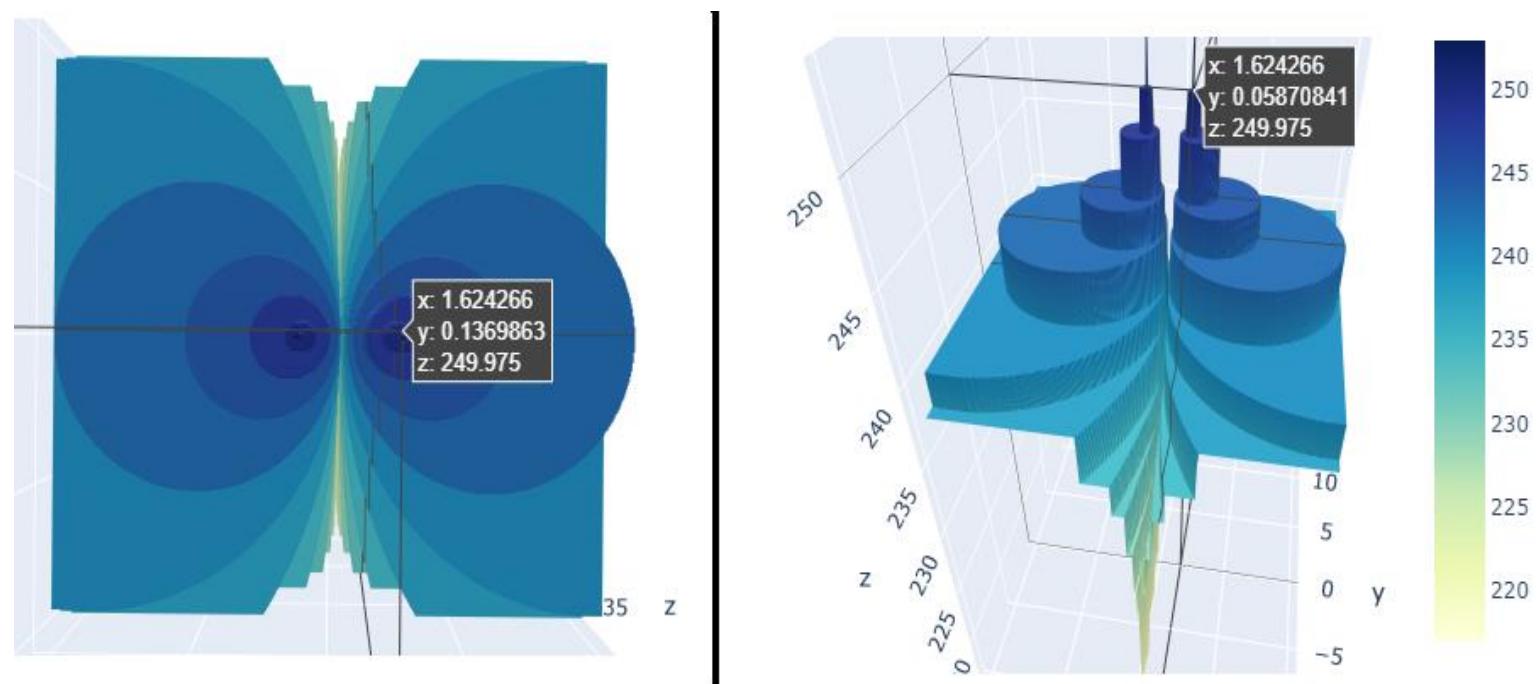

Figure 2. Newton's 3D fractal of the Fibonacci and Lucas sequence in 3D

Prepared by the authors

We can see the existence of two lobes, representing exactly the two roots of the equation $\phi^{2}-\phi-1=0$. Because they are located horizontally, we have both to be real, in addition to being on the side attached to the other, meaning that one is positive and the other negative. It is also possible to notice the presence of few colors, that is, that few iterations will be necessary to reach the exact value of these roots. In Figure 2, we have a $3 \mathrm{D}$ representation of this fractal, where when navigating with the mouse in the figure it is possible to perceive the dimensions of the root, where we have the value of $\mathrm{x}$ approximately 1.6 ; the value of $\mathrm{y}$ close to 0 , indicating that the root is not complex; and the value of $\mathrm{z}$ representing the degree of accuracy, since according to the table presented laterally, it is found that values close to 250 represent approximation with the correct value of the root under analysis. To obtain the other root, just perform the same process. (See Figure 2).

\section{Mersenne's Dractal}

For the analysis of the real root of the Mersenne sequence determined by the characteristic equation $\mu^{2}-$ $3 \mu+2=0$, based on its convergence relation seen previously, we have the Newton fractal generated by Google Colab, as shown in Figure 3. 


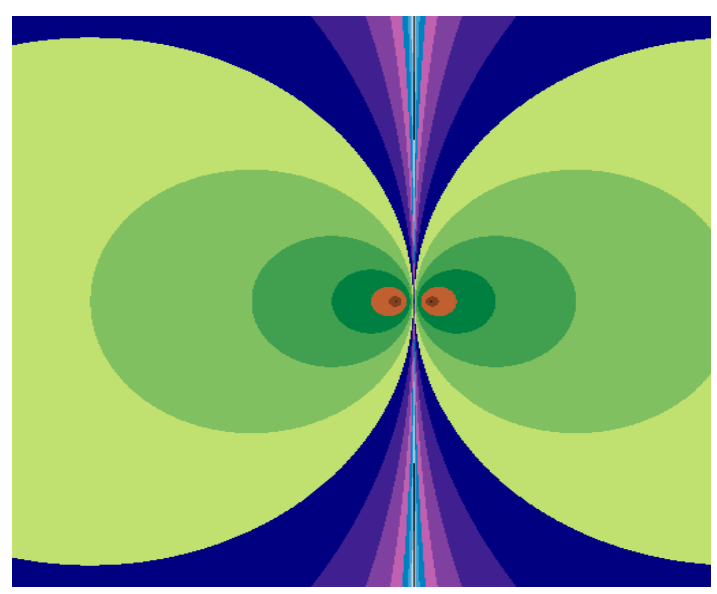

Figure 3. Newton's fractal of the Mersenne sequence Prepared by the authors
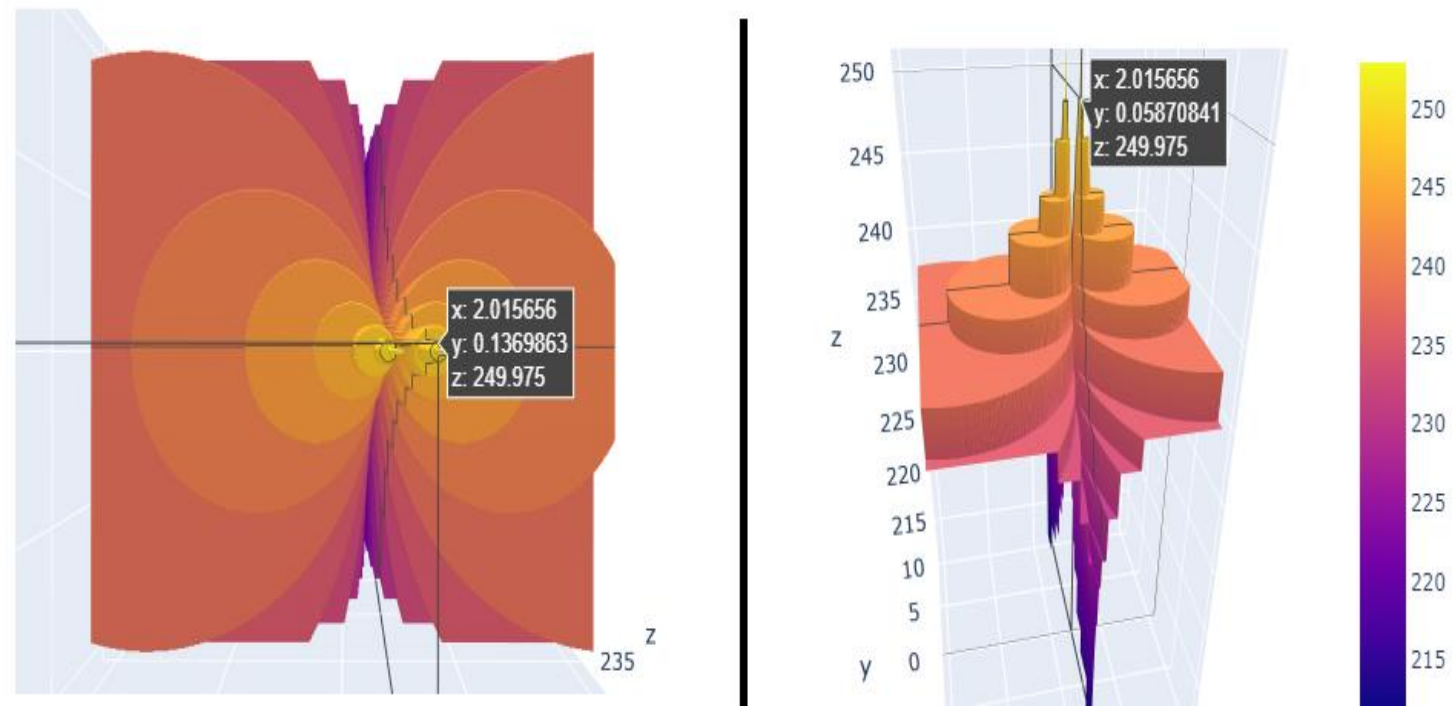

Figure 4. 3D Newton's fractal of the Mersenne sequence in 3D Prepared by the authors

As it presents a characteristic equation similar to the Fibonacci sequence, we can see some similarities with these two fractals. Thus, we visualize the presence of two real roots, and the orange lobe with a smaller appearance, highlighting that to assume a good value from the initial iteration is more difficult, since starting with values far from the correct root value, they may occur more iterations until you can get to the exact value of the real root. We also have a 3D fractal analysis, as shown in Figure 4, obtaining the root value as being approximately 2 (copper number). In a similar way to the analysis performed for the Fibonacci and Lucas fractal, the use of the scale and coordinates obtained.

\section{Oresme's fractal}

Newton's fractal of the Oresme sequence, is represented through Figure 5, in which we seek to analyze its real root determined by the characteristic equation $\sigma^{2}-\sigma+\frac{1}{4}=0$, based on its convergence relation. Thus, we observed the presence of two real and equal roots, in addition to a greater amount of colors than those presented for the previous sequences. 


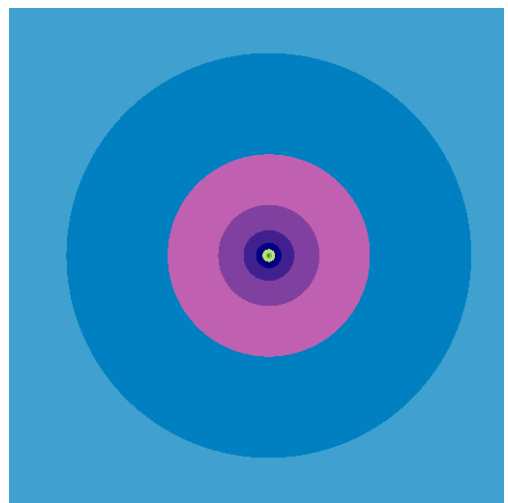

Figure 5. Newton's fractal from the Oresme sequence Prepared by the authors
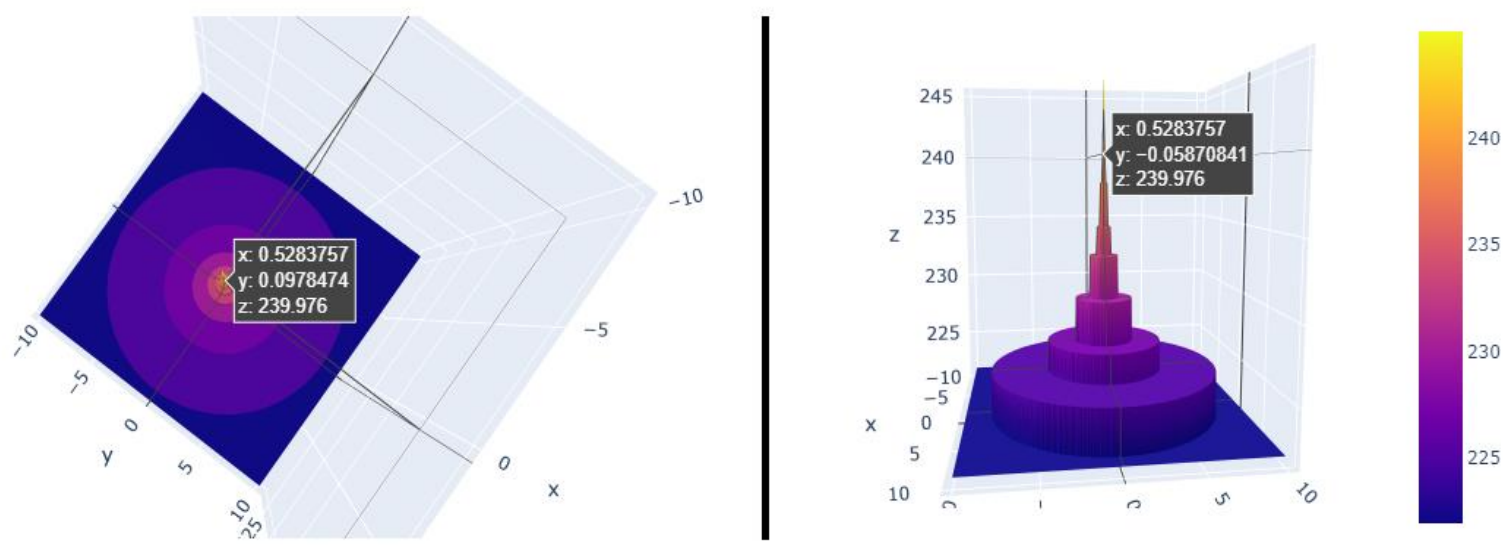

Figure 6. Newton's fractal of the Oresme sequence in 3D Prepared by the authors

Analyzing the value of this real root, as we can see, according to the coordinates in Figure 6, it is approximately 0.52 . Comparing with objects in nature, we can see the similarity of this $3 \mathrm{D}$ fractal with the human eye.

\section{Jacobsthal's fractal}

The Jacobsthal sequence has an equation very similar to the Fibonacci, Lucas, Pell and Mersenne sequence. Therefore, we notice that in Figure 7, this sequence has two real and distinct roots originating from the characteristic equation $\mu^{2}-\mu-2=0$. 


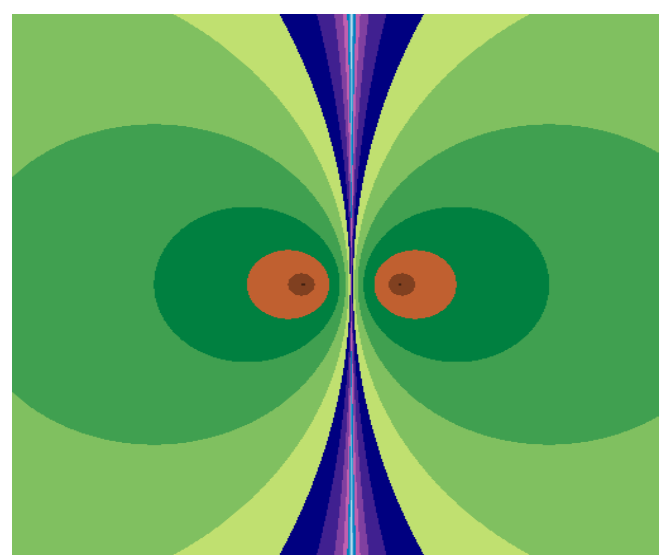

Figure 7. Newton's fractal of the Jacobsthal sequence

Prepared by the authors
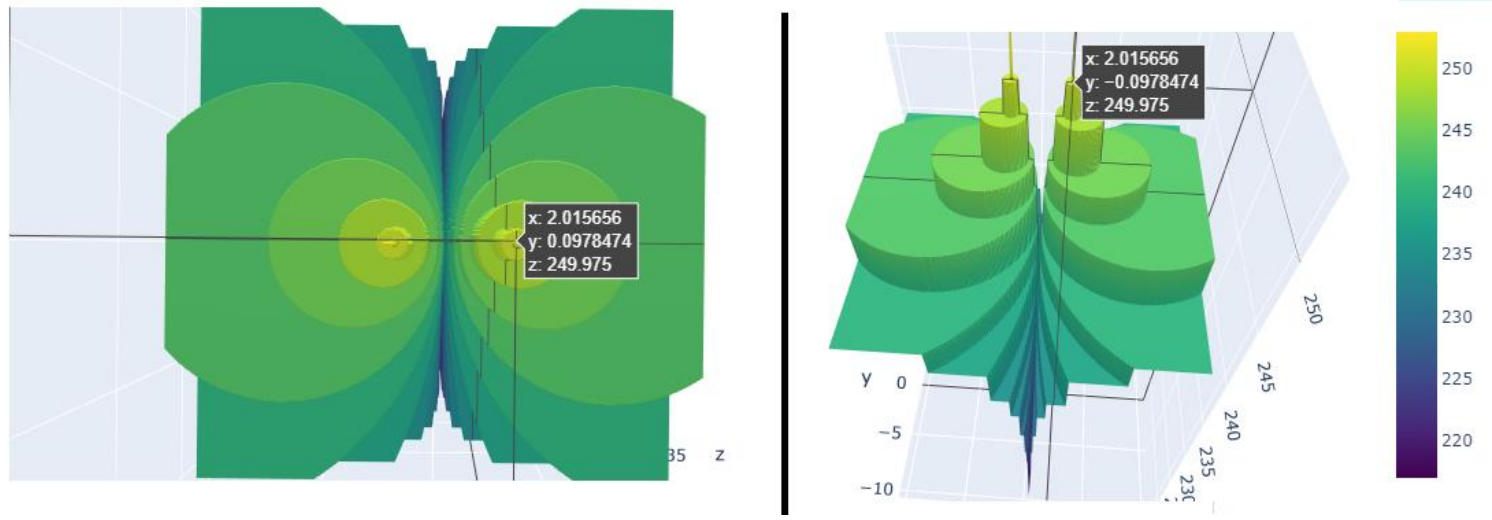

Figure 8. Newton's fractal of the Jacobsthal sequence in 3D Prepared by the authors

Analyzing the fractal in a 3D version, as shown in Figure 8, we perceive the value of the convergence ratio, given by the positive root, having approximately 2 (copper number), a value equal to that of the Mersenne sequence.

\section{Pell's fractal}

The Pell fractal, shown in Figure 9, has the presence of two real and distinct roots, also observing a similarity with the fractals presented for the second order sequence, which have real and distinct roots determined by the characteristic equation $\delta^{2}-2 \delta-1=0$. 
Figure 9. Newton's fractal of the Pell sequence

Prepared by the authors
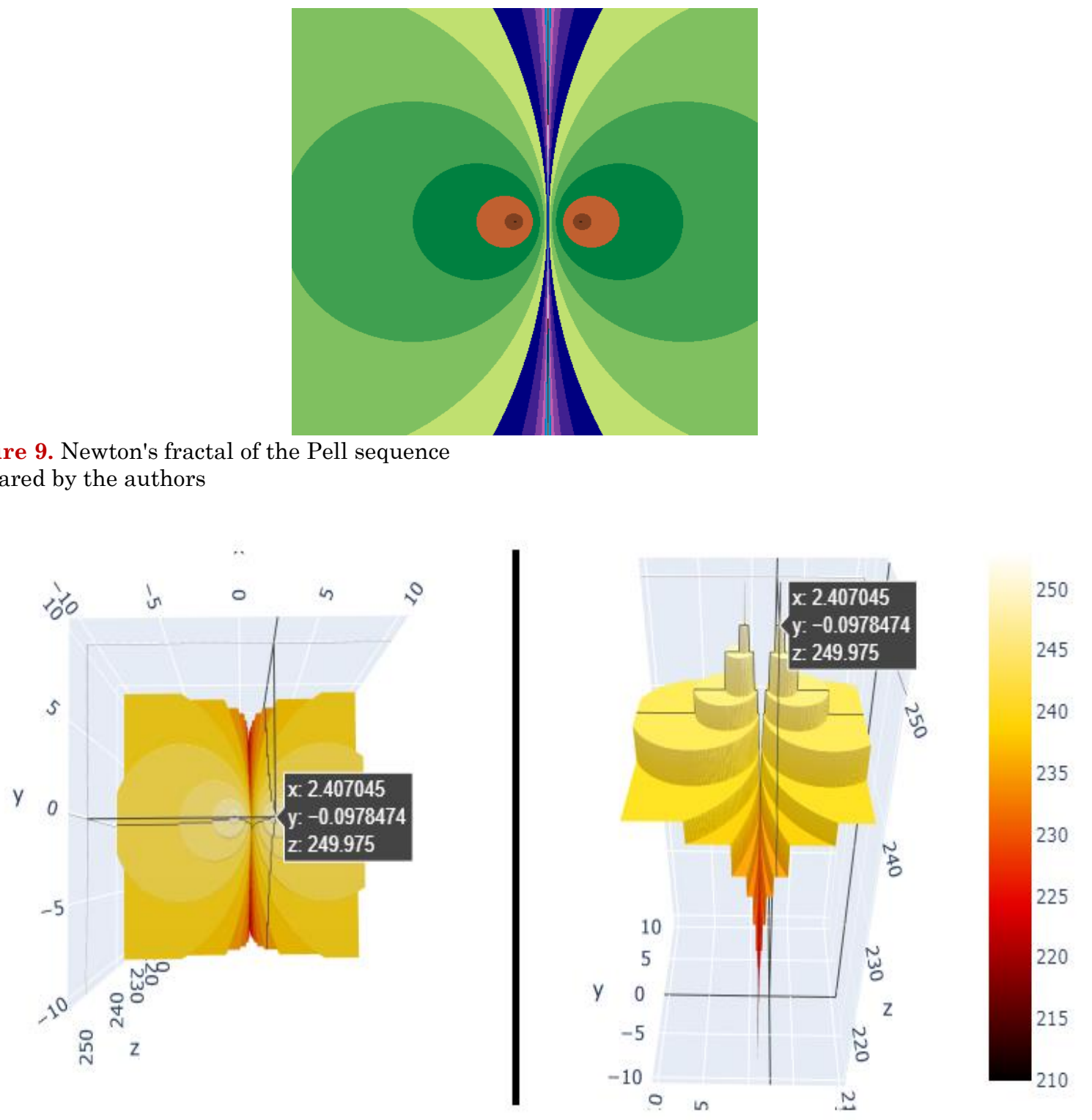

Figure 10. Newton's fractal of the Pell sequence in 3D Prepared by the authors

In order to find the value of the real root, referring to its convergence relation, we have that in Figure 10, we can obtain the approximate value of 2.41 , known as the silver number.

\section{Leonardo's fractal}

For this sequence, we have the work of Alves and Vieira (2020), in which an analysis of Newton's fractal is made in search of the roots of the characteristic equation $\phi^{3}-2 \phi^{2}+1=0$. Thus, we have in Figure 11, showing the three roots of the characteristic equation. Observing the existence of three real roots, since both are horizontal. 


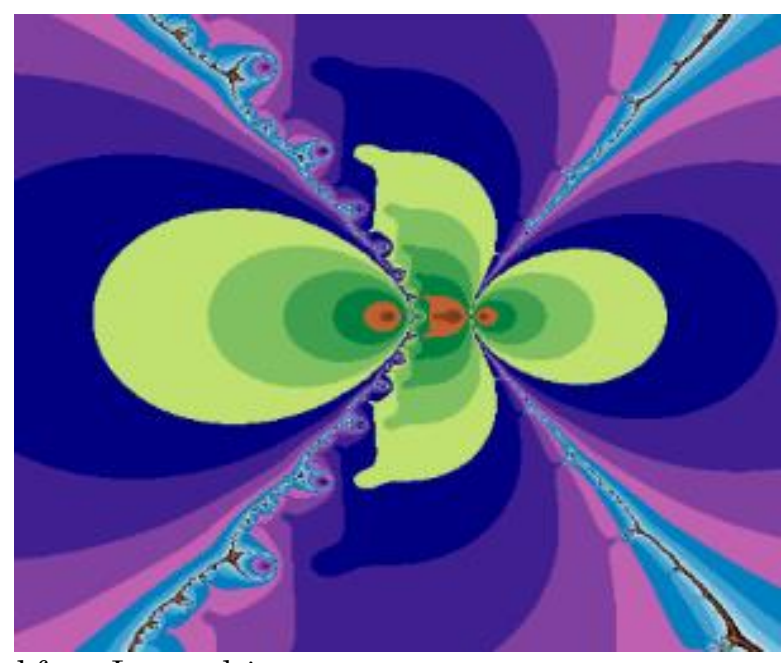

Figure 11. Newton's fractal from Leonardo's sequence

(Alves \& Vieira, 2020).
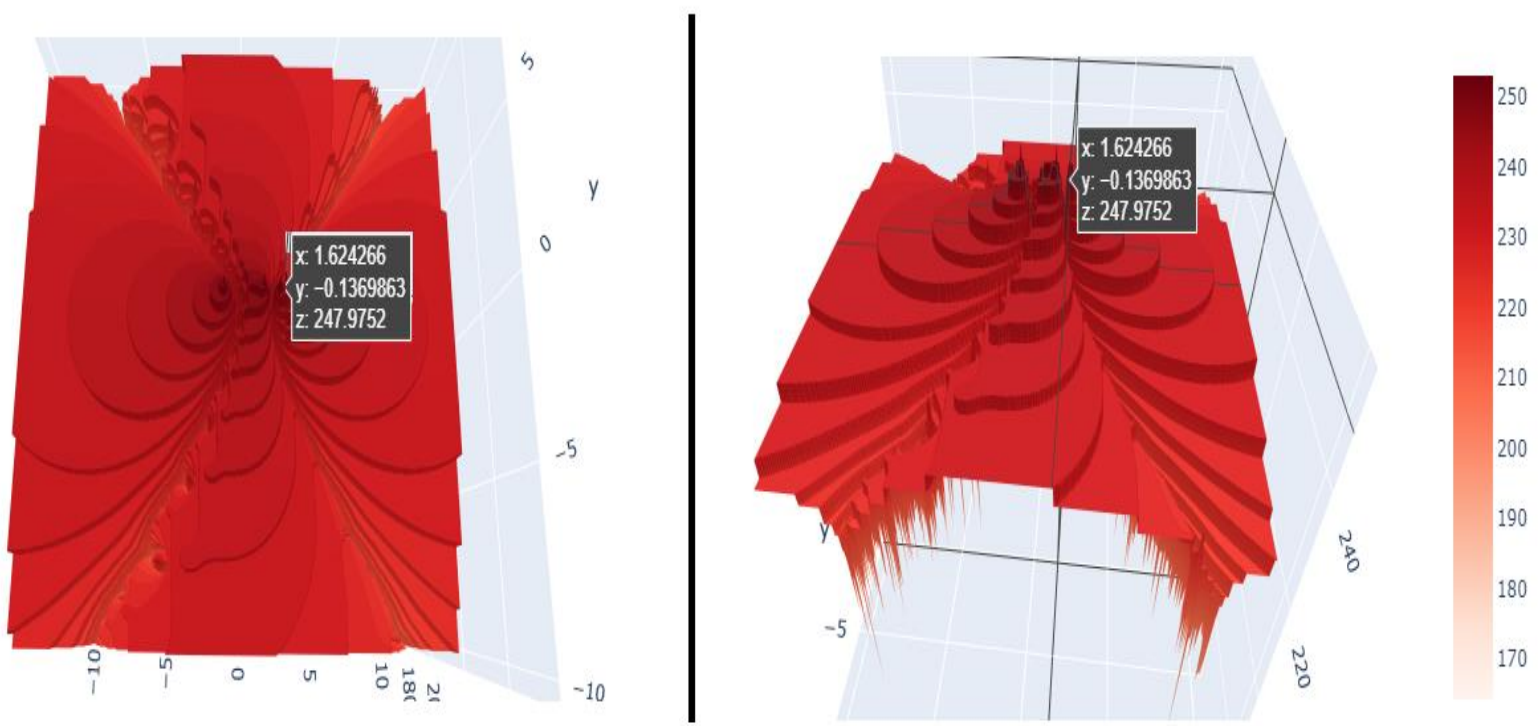

Figure 12. Newton's fractal of Leonardo's sequence in 3D

Prepared by the authors

For Figure 12, we have the 3D fractal, visualizing the approximate root value, 1.6, known as the gold number.

In this work (Alves \& Vieira, 2020), the authors still compare this fractal with the image of a bird, showing its similarity with objects found in nature.

\section{Padovan and Perrin's fractal}

Based on the work of Vieira, Alves, and Catarino (2019), in which they carry out an analysis of Newton's fractal, using the same technological tool, for Padovan's sequence, then we have Figure 13 the presence of the three roots, where two are complex and conjugated and a real one, which can be determined from the characteristic equation $\psi^{3}-\psi-1=0$. The complex roots are located vertically, emphasizing that they have $\mathrm{y}$-values, that is, they are complex. 
Figure 13. Newton's 2D fractal of the Padovan sequence

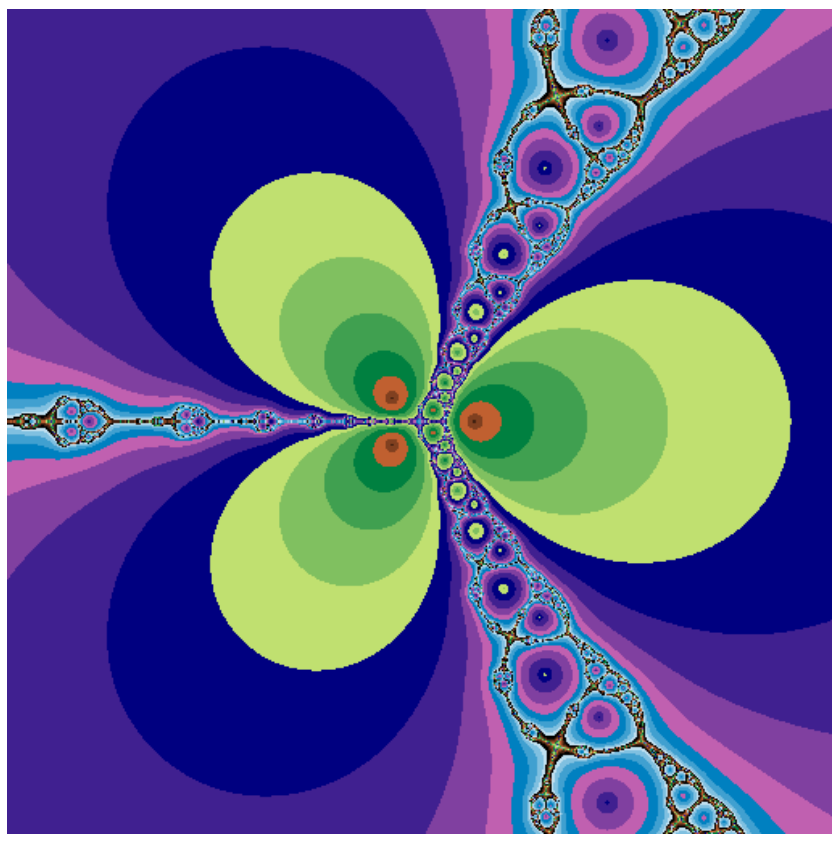

(Vieira, Alves, \& Catarino, 2019)

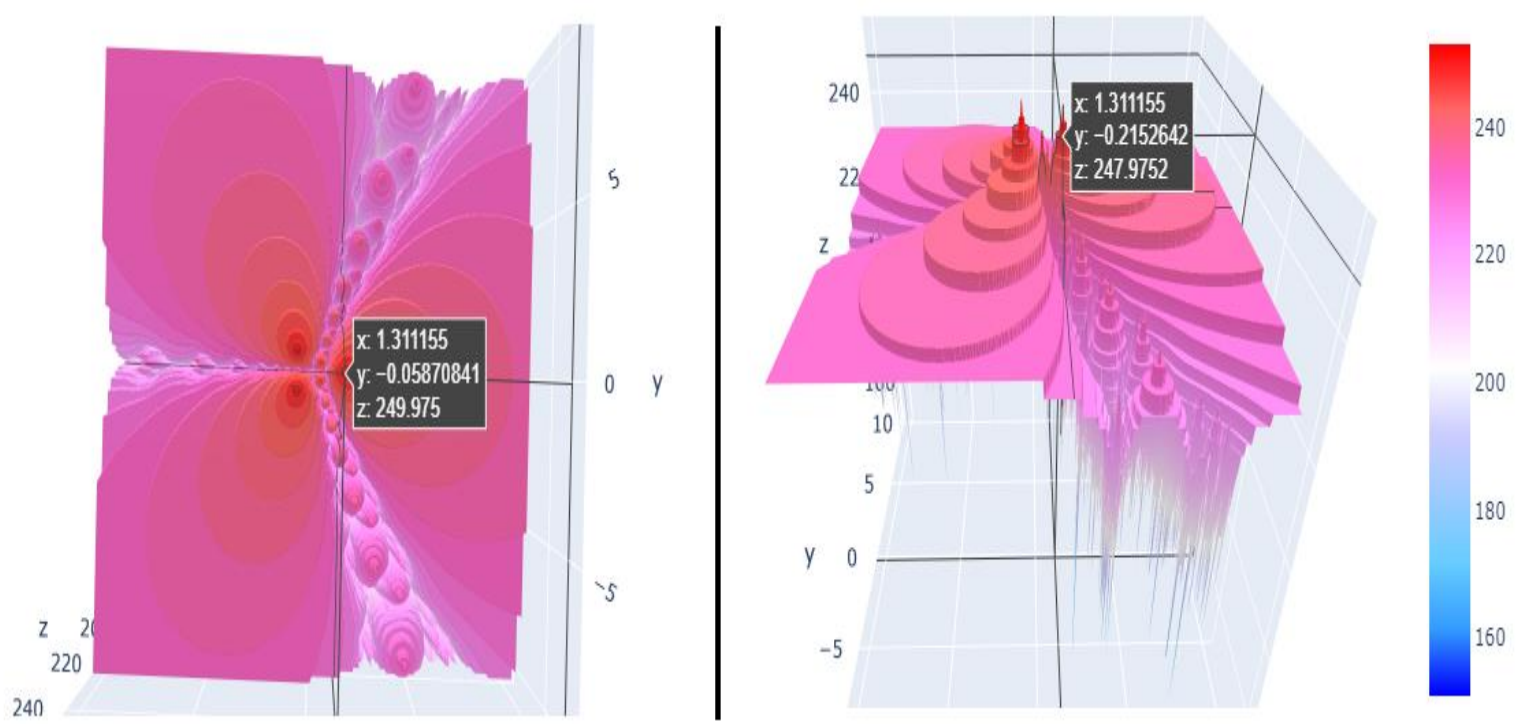

Figure 14. Newton's fractal from the Padovan sequence in 3D Leonardo

Prepared by the authors

Figure 14 shows the approximate value of the real root 1.3, known as the plastic number. The other complex roots can be obtained in a similar way, however, as this research seeks to analyze only the roots that are related to the convergence of the subsequence, they will not be analyzed in this work.

It should be noted that for the Perrin sequence, the graphs will be the same, since they have the same characteristic equation. In the work of Vieira, Alves, and Catarino (2019), the fractal of this sequence is compared to the geranium flower.

\section{Narayana's Fractal}

The Narayana sequence has its fractal plotted according to Figure 15, presenting its three roots determined by the fundamental equation $\eta^{3}-\eta^{2}-1=0$, where two are complex and conjugated and one real root. In Brazil we do not find specialized books on the History of Indian Mathematics, so we consulted other 


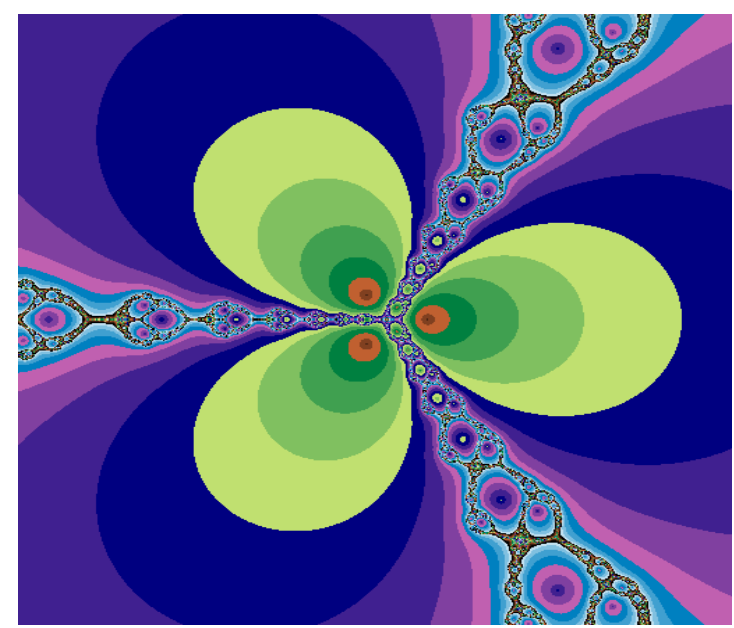

Figure 15. Newton's fractal of the Narayana sequence Prepared by the authors

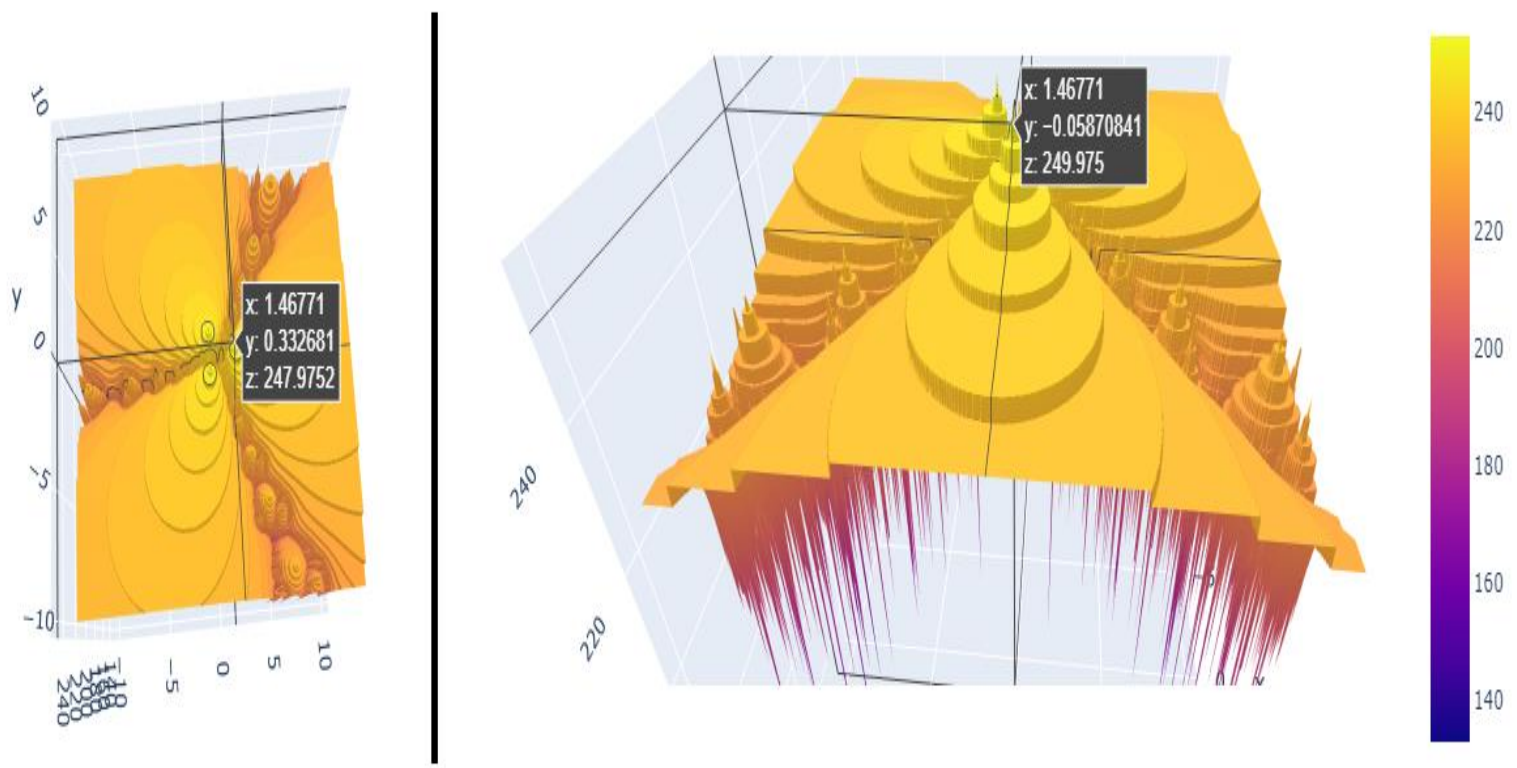

Figure 16. Newton's fractal of the Narayana sequence in $3 \mathrm{D}$

Prepared by the authors

important sources and authors who discuss the role of the Indian mathematician Narayanna (Parameswaran, 1998).

We also have, in Figure 16, the fractal representation of this sequence in 3D, where it is possible to visualize its real root, according to the convergence ratio, being approximately 1.46.

\section{CONCLUSION}

In this work it was possible to know, briefly, the historical process of linear and recurring sequences, comparing them with Fibonacci numbers, since this sequence is considered the precursor of the others. In relation to the mathematical study, their respective recurrence formulas were analyzed, performing mathematical operations, from which their respective characteristic equations.

In view of these set of characteristic equations, it was possible to use the computational tool of Google Colab, to generate fractals using Newton's method, in order to search for their real roots. Furthermore, some similarities between the generated fractals were established, with objects found in nature. It should be noted that this search for real roots has the bias of highlighting the convergence relationship between the 
neighboring terms of the sequence. Since, by dividing a term by its predecessor, that division converges to a certain numerical value, which is found in one of the real solutions of their respective characteristic polynomials.

On the other hand, the computational representations shown here, $2 \mathrm{D}$ and $3 \mathrm{D}$, which we discussed in the previous sections are an example of the role and importance of visualization, with the aim of stimulating intuition and the perception of mathematical properties that, sometimes, derive from abstract mathematical models, however, technology provides another approach and meaning bias for mathematics and, consequently, another way of providing an expanded mathematical culture to the mathematics teacher in Brazil.

We observed that the knowledge produced about the abstract notion of recurrent sequences and their interface with technology and that we potentiate learning situations involving the importance of visualization, involve an important scientific cooperation of researchers from Brazil and Portugal (Alves \& Catarino, 2019; Catarino \& Borges, 2020), in the context of the initial training of teachers of Mathematics. Thus, the results presented here can stimulate further research and professional training itineraries. For future work, a proposal is presented to apply a research and teaching methodology for mathematics teachers in initial training in Brazil. Thus, some structured didactic situations can be elaborated, so that this content is transformed into a content to be taught.

\section{Disclosure statement}

No potential conflict of interest was reported by the authors.

\section{Notes on contributors}

Francisco Regis Vieira Alves - Federal Institute of Science and Technology of Ceara, Brazil.

Renata Passos Machado Vieira - Federal Institute of Education, Science and Technology, Fortaleza, Brazil.

Paula Maria Machado Cruz Catarino - UTAD - University of Trás-os-Montes and Alto Douro, Portugal.

\section{REFERENCES}

Adamns, D. (1982). Mathematics of Computation. American Mathematical Society, 39(159).

Alves, F. R. V., \& Vieira, R. P. M. (2020). The Newton Fractal's Leonardo Sequence Study with the Google Colab. International Electronic Journal of Mathematics Education, 15(2), 1-9. https://doi.org/10.29333/iejme/6440

Alves, F. R. V. (2019). Sequência de Oresme e algumas propriedades (matriciais) generalizadas. C.Q.D. Revista Eletrônica Paulista de $\quad$ Matemática, $\quad 16, \quad$ 28-52. https://doi.org/10.21167/cqdvol16201923169664frva2852

Alves, F. R. V. (2017). Engenharia Didática para a s-Sequência Generalizada de Jacobsthal e a (s,t)-Sequência Generalizada de Jacobsthal: análises preliminares e a priori. Revista Iberoamericana de Educación Matemática, 51, 83-106.

Alves, F. R. V. (2016). Sequência generalizada de Pell (SGP): aspectos históricos e epistemológicos sobre a evolução de um modelo. Revista Thema, 13(2), 27-41. https://doi.org/10.15536/thema.13.2016.27-41.324

Alves, F. R. V., \& Catarino, P. M. (2019). Situação Didática Profissional: um exemplo de aplicação da Didática Profissional para a pesquisa objetivando a atividade do professor de Matemática no Brasil. Indagatio Didactica 11(1), 1-30. https://doi.org/10.34624/id.v11i1.5641

Assis, T. A., Miranda, J. G. V., Mota, F. de B. R., Andrade, F. S., \& Castilho, C. M. C. (2008). Geometria fractal: propriedades e características ideais. Revista Brasileira de Ensino de Física, 30(2), 2304-01-2304-10. https://doi.org/10.1590/S1806-11172008000200005

Catarino, P., \& Borges, A. (2020). On Leonardo numbers. Acta Mathematica Universitatis Comenianae, 1(89), 75-86.

Catarino, P. M. M. C., Campos, H., \& Vasco, P. (2016). On the Mersenne sequence. Annales Mathematicae et Informaticae, 46, 37-53. 
Craveiro, I. M. (2004). Extensões e Interpretações Combinatórias para os Números de Fibonacci, Pell e Jacobsthal. 117 f. Tese de doutorado - Instituto de Matemática, Estatística e Computação Científica, UNICAMP, Campinas, São Paulo. https://doi.org/10.5540/tema.2004.05.02.0205

Forbes, T. (2014). Linear recurrences sequences. in Talks given at LSBU, 1-6.

Ford, K., Luca, F., \& Shparlinski, I. E. (2009). On the largest prime factor of the Mersenne numbers. Bulletin of the Australian Mathematical Society, 79, 455-463. https://doi.org/10.1017/S0004972709000033

Horadam, A. F. (1974). Oresme numbers. Fibonacci Quarterly, 12, 267-271.

Kaplansky, I. (1943). Solution of the \&quot; Problème des ménages\&quot. Bulletin of the American Mathematical Society, 49(10), 784-785. https://doi.org/10.1090/S0002-9904-1943-08035-4

Knott, R. (06 Jan. 2020). The Mathematical Magic of the Fibonacci Numbers. 2Surrey.ac.uk. University of Surrey.

Koshy, T., \& Gao, Z. (2013). Catalan numbers with Mersenne subscripts. Mathematical Scientist, 38, 86-91.

Koshy, T. (2001). Fibonacci and Lucas Numbers with Application. A Wiley Interscience Publication. John Wiley \& Sons. https://doi.org/10.1002/9781118033067

Malcolm, N. (2000). The publications of John Pell, F. R.S (1611 - 1685): some new lights and some old confusions. Notes and Records of the Royal Society of London, 54(3), 275-292. https://doi.org/10.1098/rsnr.2000.0113

Oliveira, R. R., \& Alves, F. R. V. (2019). An investigation of the Bivariate Complex Fibonacci Polynomials supported in Didactic Engineering: an application of Theory of Didactics Situations (TSD). Revista Acta Scientiae, 21, 170-195. https://doi.org/10.17648/acta.scientiae.v21iss3id3940

Parameswaran, S. (1998). The Golden Age of Indian Mathematics, Indian: Swadeshi Kerala.

Protázio, A. dos A., Oliveira, M. de F. S. dos S., \& Protázio, A. dos S. (2019). Análise de software para o ensino de evolução através de critérios pedagógicos e computacionais. Revista Iberoamericana de Tecnología en Educación y Educación en Tecnología, 24, 44-55. https://doi.org/10.24215/18509959.24.e06

Ramirez, J. L., \& Sirvent, V. F. (2015). Uma nota sobre a sequência k-Narayana. Ann. Matemática. Inform, 45, 91-105.

Shannon, A. G. (2019). A note on generalized Leonardo numbers. Note on Number Theory and Discrete Mathematics, 25(3), 97-101. https://doi.org/10.7546/nntdm.2019.25.3.97-101

Singh, P. (1985). The So-called Fibonacci Numbers in Acient and Medieval India, Historia Mathematica, 12(1), 229-244. https://doi.org/10.1016/0315-0860(85)90021-7

Souza, T. S. A., \& Alves, F. R. V. (2018). Engenharia didática como instrumento metodológico no estudo e no ensino da Sequência de Jacobsthal. Tear: Revista de Educação, Ciência e Tecnologia, 7(1), 1-30. https://doi.org/10.35819/tear.v7.n2.a3119

Takayasu, H. (1990). Fractals in the Physical Sciences Manchester Univ. Press, Manchester.

Teodoro, M. M., \& Aguilar, J. C. Z. (2015). O método de Newton e fractais. Dissertação de Mestrado Profissional em Matemática - Universidade Federal de São João del-Rei.

Vieira, R. P. M., Alves, F. R. V., \& Catarino, P. M. M. C. (2019). Alternative views of some extensions of the padovan sequence with the Google Colab. Anale. Seria Iformatica, XVII(2), 266-273.

Vieira, R. P. M., Alves, F. R. V., \& Catarino, P. M. M. C. (2019). Relações bidimensionais e identidades da sequência de Leonardo. Revista Sergipana de Matemática e Educação Matemática, 4(2), 156-173. https://doi.org/10.34179/revisem.v4i2.11863

Voet, C., \& Schoonjans, Y. (2012). Benidictine thought as a catalist for 20tm century liturgical space: the motivation behind dom hans van der laan s aesthetic church arquitectury. Proceeding of the 2nd international conference of the Europa Architetural History of Network, 255-261.

Walker, I. I. (2011). Explorations in Recursion with John Pell and the Pell Sequence: Recurrence Relations and their Explicit Formulas (Dissertation - Master in Mathematics), Portland: Portland State University.

Zierler, N. (1959). Linear recurring sequences. Journal of the Society for Industrial and Applied Mathematics, 7(1), 31-48. https://doi.org/10.1137/0107003 